\title{
Um estudo qualitativo sobre a transferência na aprendizagem de espanhol por alunos brasileiros
}

Gisele Benck de Moraes"

Marília dos Santos Lima**

\section{Resumo}

Este estudo trata de questões relativas à transferência da língua materna para a língua espanhola, focalizando o uso do presente do subjuntivo com a conjunção subordinada adverbial cuando. Os dados foram coletados em uma turma de alunos de Letras, em uma universidade privada no sul do Brasil. Atividades orais e escritas foram aplicadas no decorrer do processo. Recorremos ao programa Team Speak para a realização de entrevistas narrativas com os alunos envolvidos no estudo. Os depoimentos dos alunos evidenciam a relevância dos itens linguísticos focalizados e o uso do programa Team Speak como uma ferramenta auxiliar para a aprendizagem da língua-alvo.

Palavras-chave: Transferência. Presente do subjuntivo. Team Speak. Entrevista narrativa. Espanhol.

\section{Introdução}

Este artigo foi escrito com o propósito de analisar como a questão da transferência pode ser evidenciada na aprendizagem de uma nova língua, no caso deste estudo, a língua espanhola. Para verificar esse processo de transferência, utilizamos atividades que exigiam o uso do presente do subjuntivo em espanhol com a conjunção subordinada adverbial cuando, e recorremos a uma entrevista narrativa realizada com os participantes da investigação a fim de evidenciar as percepções dos participantes sobre seu

Doutora em Linguística Aplicada pela Universidade do Vale do Rio dos Sinos (2014). Atualmente é professora titular I do curso de Letras da Universidade de Passo Fundo. E-mail: gbenck@upf.br

** Doutora em Ciência Linguística (Linguística Aplicada) pela Universidade de Reading, Reino Unido. Professora e orientadora do Programa de Pós-Graduação em Linguística Aplicada da Universidade do Vale do Rio dos Sinos. E-mail: marilialim@unisinos.br

Data de submissão: set. 2015 - Data de aceite: nov. 2015 http://dx.doi.org/10.5335/rdes.v11i2. 5371 
processo de aprendizagem e o fenômeno observado na aprendizagem da língua estrangeira.

Nos estudos sobre a aquisição ${ }^{1}$ do espanhol como língua estrangeira ${ }^{2}$ (LE), em distintos contextos de ensino, os resultados apontam para algumas dificuldades encontradas por alunos brasileiros, no que se refere à aprendizagem de formas linguísticas, especialmente em nível lexical (VILLALBA, 2002) e morfossintático (BOÉSSIO, 2003; COSTA, 2004). Muitas dessas dificuldades são devidas à transferência linguística da língua materna. Esse é o caso do presente do subjuntivo.

Temos verificado, como professores de ensino superior, no curso de Letras, que os alunos não empregam adequadamente a forma verbal presente do subjuntivo em orações subordinadas adverbiais, como no caso de cuando + presente de subjuntivo + futuro imperfecto de indicativo (Cuando llegue, hablaré contigo), com ideia de futuro, uma vez que existe a tendência de emprego de infinitivo flexionado, em vez do presente do subjuntivo. Além disso, observamos que os alunos, mesmo em estágio de conclusão do curso de Letras, apresentam construções como: "Cuando yo viajar, compraré regalos", em vez de "Cuando yo viaje, compraré regalos". Logo, existe a tendência de o aprendiz utilizar, erroneamente, o infinitivo pessoal, como acontece no português brasileiro, ou seja, ele transfere o emprego do verbo no infinitivo com a marca de pessoa do discurso em orações temporais, conforme uso do português brasileiro, evidenciado por Boéssio (2003).

Portanto, ao constatarmos esses erros, ${ }^{3}$ de utilização do presente do subjuntivo em espanhol, observamos a transferência da língua materna (doravante LM) para a LE, principalmente no uso de cuando, pois o aluno tende a utilizar o infinitivo, flexionado ou não, depois da conjunção adverbial temporal.

Neste artigo, trataremos da transferência linguística, apresentando um breve histórico e focalizando alguns estudos realizados por pesquisadores brasileiros. Também apresentaremos dados de uma pesquisa envolvendo entrevistas narrativas realizadas com alunos universitários participantes da investigação sobre o uso do subjuntivo. Para a realização da entrevista narrativa, utilizamos o programa Team Speak, que será caracterizado posteriormente, estabelecendo uma conexão entre aprendizagem, uso de língua e ferramenta digital.

\section{Breve histórico da transferência}

Segundo Odlin (1989), sempre que duas línguas entram em contato, uma necessidade de comunicação linguística é estabelecida e há uma chance muito grande de que haja uma mistura linguística na hora da produção verbal dos falantes.

$\mathrm{Na}$ primeira metade do século XX, a noção de transferência ocupou uma posição central na escola behaviorista 
(GASS; SELINKER, 2008). Naquela época, o termo transferência era proveniente da Psicologia da Aprendizagem e referia-se ao processo psicológico pelo qual um conhecimento prévio era transferido e aplicado a uma nova situação de aprendizado. Nesse sentido, compreendia-se o ato de aprender como um processo cumulativo, que consistia em se formarem hábitos. Já no contexto de aquisição de LE, transferência era a construção de um conjunto de hábitos para a produção e a compreensão oral de enunciados naquela língua (SELINKER, 1992).

Os linguistas behavioristas viam na língua materna um elemento dificultador da aquisição da LE. Nesse contexto, surge a análise contrastiva (doravante AC) com o objetivo de promover o estudo comparativo das línguas. Buscava-se, por meio de comparações, mapear quais áreas do sistema linguístico ofereciam maior dificuldade ou facilidade ao falante da LM no aprendizado de uma LE (GASS; SELINKER, 2008). A AC concebia o processo de aquisição de uma nova língua como formação de novos hábitos, e fundamentava-se em teorias behavioristas para a elaboração de seu arcabouço teórico, bem como na linguística estrutural.

Naquela época, para que estudos acontecessem, eram elaborados materiais didáticos específicos para os falantes de línguas diferentes e acreditava-se nos seguintes pressupostos teóricos: a) a LM era a principal fonte de erros para a produção e compreensão de enunciados realizados na língua-alvo; b) os equívocos presentes na língua do aprendiz podiam ser explicados a partir das diferenças entre a LM e a LE; c) quanto maiores fossem as diferenças entre a LM e a LE, mais erros iriam acontecer; d) a tarefa de aprender uma segunda língua consistia também em aprender as diferenças entre essas línguas (GASS; SELINKER, 2008).

Mas, com o passar do tempo, a AC pareceu ser incapaz de acompanhar as mudanças constantes dos modelos de análise e as abordagens teóricas e só conseguia explicar parte dos problemas de aprendizagem enfrentados pelos aprendizes. Os pontos das reais dificuldades, que eram mapeados, pareciam ter causas variadas entre os diferentes aprendizes, e observavam-se, também, diferenças entre a produção e a percepção da nova língua que estava sendo adquirida.

Contudo, as limitações da AC não apagaram a contribuição oferecida a outras áreas de estudo, como a tradução, a descrição de línguas específicas, a tipologia linguística e o estudo dos universais linguísticos.

A partir da metade dos anos 1970, o papel da LM na aquisição de LE foi novamente avaliado. Conforme Gass e Selinker (2008), estudos realizados apresentaram evidências favoráveis da influência da LM na aquisição de LE. O interesse naquele momento não era mais recusar ou aceitar o papel da LM, mas determinar como e quando os aprendizes utilizavam a LM e que explicações podiam ser dadas para esse fato (LONG, 
1991; ELLIS, 1995). A transferência passou a ser estudada de maneira mais qualitativa e houve um entendimento de que o fenômeno não era um conceito exclusivo do behaviorismo e que podia ser inserido em uma visão consistente com uma abordagem mentalista da linguagem (GASS; SELINKER, 2008).

Nesse sentido, estudiosos passaram a encarar a língua do aprendiz como um processo de testagem de hipóteses, por meio do qual se criam elementos extraídos dos dados da LM que podem contribuir para o uso em LE. A posição dos autores concilia hipóteses advindas da AC com princípios cognitivistas, considerando ser possível compatibilizar duas visões a respeito da aquisição de uma LE, que em épocas anteriores eram vistas como antagônicas, o que abre uma nova possibilidade de estudos e uma atualização e ressignificação do conceito de transferência linguística. Nessa mesma linha, Corder (1967) afirmou que a LM é uma ferramenta que auxilia o aprendiz na descoberta das propriedades formais da LE, sobretudo nas áreas em que essas línguas compartilham semelhanças.

A partir dos anos 1990, a transferência passou a ser estudada sob outro prisma e a possibilidade de estudos tem aumentado, contemplando não somente investigações sobre o papel da LM na aquisição de LE, mas também a influência de outras línguas já adquiridas pelos falantes.

Então, por que pesquisar se a língua materna (português do Brasil) é fator de interferência na produção oral e escrita de aprendizes do presente do subjuntivo em espanhol? Para compreendermos melhor o processo de aquisição de tempos verbais.

Para Schachter,

[...] às vezes os aprendizes são pressionados a produzir além de seu nível real de competência e não têm outra solução a não ser usar formas ou estruturas de sua primeira língua até que consigam adquirir as formas adequadas dessa língua alvo (1995, p. 227).

Percebemos, contudo, que nem sempre é isso que acontece, principalmente com o uso do presente do subjuntivo em espanhol. Muitas vezes, alunos de nível intermediário, que já trabalharam e, supostamente, aprenderam o uso desse tempo verbal, utilizam, equivocadamente a estrutura em questão em frases e produções orais e escritas.

De acordo com Koda (1997), algumas línguas podem ser consideradas mais similares entre si do que outras, como no caso do português e do espanhol. Essa similaridade pode estar relacionada ao uso de determinados mecanismos de processamento da língua na hora da aprendizagem. No caso de um aluno brasileiro aprendendo espanhol, essa proximidade linguística acionaria procedimentos similares de processamento de ambos os códigos linguísticos, o que, para Koda, seria um princípio de semelhança facilitador de aquisição, o que poderia ocasionar uma melhor competência do aprendiz.

Para Mitchell, Myles e Marsden (2013), uma forma ou estrutura gramatical ocorrerá consistentemente, e de forma 
significativa, na língua do aprendiz como resultado de uma transferência se, e apenas se: a) os princípios de aquisição natural forem consistentes com a estrutura da LM ou b) já existe dentro do insumo de LE o potencial para a generalização do insumo para produzir a mesma forma ou estrutura.

Jarvis (2000) acredita que deva existir um maior rigor metodológico nos estudos sobre transferência. Mas, para isso, é preciso levar em consideração três aspectos: a) esclarecer até que ponto a influência da LM responde pelos erros do aluno; b) conhecer as limitações e os fatores que interagem com essa influência; c) avançar nas investigações teóricas sobre transferência.

No final do estudo aqui relatado, esperamos conseguir prospectar alguns caminhos quanto a esses três aspectos referidos no parágrafo anterior, pois acreditamos que eles sejam de máxima importância para responder à questão principal em relação à transferência, abordada neste estudo: a língua materna (português do Brasil) é fator de interferência na produção oral e escrita do presente do subjuntivo em espanhol por alunos brasileiros, especialmente ao produzirem o presente do subjuntivo?

Para aprofundar e evidenciar questões de transferência do português para o espanhol, a seguir, apresentamos uma revisão de estudos sobre transferência, que se destacam no contexto brasileiro, embora não tratem especialmente do uso do subjuntivo.

\section{Estudos sobre transferência no contexto brasileiro}

Não podemos dizer que há uma grande variedade de estudos sobre a transferência linguística em contexto brasileiro. No entanto, um dos principais estudos que se ocupou acerca da transferência foi realizado por Villalba (2002). A autora investigou a transferência linguística e os indícios de fossilização no conhecimento lexical em espanhol de universitários brasileiros. Para Villalba, transferência não é apenas um fenômeno linguístico, mas também é uma estratégia de aprendizagem. A investigadora hipotetiza - e corroboramos com sua teoria - que a semelhança entre as duas línguas implicadas favorecerá a ocorrência da transferência.

No caso do nosso estudo, embora os alunos tenham estudado e supostamente aprendido o presente do subjuntivo em nível anterior, quando os dados foram coletados, utilizando a abordagem comunicativa, eles não manifestaram a aquisição ou não recordavam como utilizar o tempo verbal em questão.

Para a execução da pesquisa, Villalba (2002) contou com a participação de 58 estudantes de duas universidades públicas no sul do Brasil, todos cursando uma das modalidades de licenciatura (simples ou dupla) ou bacharelado (tradução) em espanhol. Os participantes foram divididos em três grupos de alunos: básico, intermediário e avançado. Os alunos de nível básico compreendiam $80 \%$ da faixa 
etária entre 18 e 23 anos, os de nível intermediário, 35\% entre 20 e 26 anos e $45 \%$ entre 28 e 38 anos, os de nível avançado; avançado, $75 \%$ entre 21 e 29 anos. Todos os participantes apresentavam como língua materna o português.

No início da investigação foi aplicado um questionário pessoal para obter o perfil dos participantes. Ao longo da investigação foi aplicado um conjunto de testes (LAUFER, 1998), conhecido como enfoque de testes múltiplos, pois mede diferentes aspectos do conhecimento lexical, a saber: teste de conhecimento passivo, ${ }^{4}$ conhecimento ativo, controlado e de produção livre.

Das várias questões discutidas por Villalba (2002), interessa-nos, particularmente as seguintes observações: a) quanto ao mito de o espanhol ser uma língua fácil, no caso particular do aluno brasileiro aprendendo espanhol, existem indícios de que a dificuldade tem a ver também com a falsa semelhança e principalmente com a dicotomia semelhança/ falsa semelhança em termos de definição de limites linguísticos entre os dois sistemas; b) a transferência também pode ser vista como uma questão de autonomia em relação à língua materna e ser desdobrada em vários questionamentos que expliquem a relação entre a L1 e a L2.

Como o presente estudo buscou analisar como a LM influencia a transferência de formas linguísticas para a língua-alvo, como no caso de cuando em oração temporal, podemos citar também uma pesquisa que investiga a transferência do infinitivo flexionado no ensino do espanhol para brasileiros, uma vez que o erro com cuando pode acontecer pelo mesmo fator determinante que influencia a transferência do infinitivo.

Boéssio (2003) tem como objetivo geral verificar os usos do infinitivo no espanhol e no português. Os objetivos específicos são: constatar que o problema está na flexão do infinitivo, devido ao fato de não existir essa construção no espanhol; registrar essa ocorrência e buscar alternativas para minimizá-la; identificar em que contextos linguísticos ocorrem com maior frequência as transferências indevidas; avaliar a consciência de professores e alunos (formandos) do curso de Letras - espanhol; observar nos materiais didáticos de ensino de espanhol para brasileiros a preocupação com o fenômeno linguístico em questão.

Nesse estudo, Boéssio faz uma afirmação que vem ao encontro da investigação:

A utilização do quando com ideia de futuro é motivo de transferência indevida por alunos brasileiros aprendizes de espanhol. Os aprendizes utilizam a construção do Português, quando deveriam utilizar o presente do subjuntivo que expressa essa ideia de futuro no Espanhol. No Português, é comum a construção: "Quando chover eu estudo". No Espanhol, essa construção não seria possível, e sim: "Cuando llueva, estudio (2003, p. 48 , grifo do autor).

Para a realização da investigação, Boéssio (2003) selecionou quatro grupos distintos. $\mathrm{O}$ primeiro com sete alunos do quarto semestre de Turismo de uma universidade do sul do país, o segundo 
com 24 alunos do quarto semestre do curso de Letras da mesma instituição, o terceiro com treze alunas, formandas, também do curso de Letras - espanhol, e o quarto grupo com onze professores de diversos níveis de ensino e diferentes regiões geográficas.

Foram aplicadas diferentes atividades ao longo da pesquisa. Para o primeiro grupo, utilizou-se um instrumento de pesquisa com exercícios direcionados para verificar o aparecimento da flexão e também para avaliar a consciência desses alunos a respeito de construções gramaticais equivalentes em espanhol. Para o segundo grupo, foi realizada uma coleta de textos, aproveitando-se os fragmentos em que havia ocorrências. Para os dois últimos grupos, foi aplicado um questionário para verificar a consciência ou não do infinitivo flexionado como transferência indevida no aprendizado de espanhol por estudantes brasileiros.

Em resposta ao objetivo geral, e após análise dos dados, Boéssio (2003) conclui que, na maioria dos casos, o uso do infinitivo coincide no espanhol e no português, não causando maiores dificuldades no aprendizado de espanhol como LE. O problema, segundo a autora, realmente aparece quando se tenta responder a um objetivo específico, quando em português são realizadas construções com o infinitivo flexionado, já que os professores, em geral, não mostram, por meio da análise contrastiva, as equivalências possíveis, isto é, não chamam esse aspecto gramatical à consciência do aluno. Essa ausência de discussão deve-se, em grande parte, ao desconhecimento do fato linguístico em sua própria língua - caso de professores brasileiros de espanhol - ou de desconhecimento da língua materna do aprendiz - caso de professores nativos de espanhol.

Os contextos linguísticos propícios à transferência indevida da flexão do infinitivo, de acordo com os dados da investigação, foram: em primeiro lugar, as construções finais, dado que, em português, as orações reduzidas de infinitivo adverbiais finais formam contexto ideal para a flexão do infinitivo, sendo, assim, transferidas para a LE. Acrescente-se, ainda, o fato de que, em espanhol, há a possibilidade do uso do infinitivo não flexionado quando existe igualdade do sujeito na oração principal e na subordinada.

Em resposta ao objetivo que buscava avaliar a consciência dos professores de espanhol e concluintes do curso de Letras - espanhol, verifica-se que a maioria, tanto de alunos como de professores, não tem o real conhecimento da questão abordada. De um total de 13 formandas, somente três demonstraram conhecimento a respeito. Dos nove professores de espanhol, somente dois mostraram-se familiarizados com o tópico em estudo.

$\mathrm{E}$, em relação aos livros didáticos, com referência à flexão do infinitivo e ao uso do subjuntivo, a autora verificou, nos três livros analisados, que já existem autores-linguistas preocupados com essa ocorrência. Não foram encontrados, contudo, estudos que levassem essa questão adiante e aprofundassem a investigação. 
Outro estudo relacionado à transferência linguística foi realizado por Cruz (2001). A autora efetuou um estudo longitudinal com o propósito de mapear a produção oral dos sujeitos aprendizes de espanhol de um curso de Letras de uma universidade pública paulista, do primeiro ao quarto ano. Trata-se de uma pesquisa qualitativa, de cunho interpretativista, que se propôs dar conta dos dados linguísticos examinando também o contexto de ensino em que ocorrem as vivências acadêmicas e pessoais dos sete sujeitos participantes.

Como instrumentos de coleta de dados em Cruz (2001), foram delimitadas as observações das aulas, os exames orais e outras atividades propostas pelas professoras de língua espanhola. Nos terceiro e quarto anos, a pesquisadora contou com a participação dos professores de literatura espanhola, literatura hispano-americana e prática de ensino de espanhol. Para a análise dos dados, a investigadora utilizou os seguintes instrumentos: no primeiro ano de pesquisa, gravação de vídeo/aulas (três aulas) e gravação de vídeo/conversação com os professores participantes; no segundo ano, gravação de vídeo/aulas (duas aulas), gravação de vídeo/exame conversação, gravação áudio/comentário - laboratório, gravação áudio/aula novamente e gravação áudio/exame de conversação (duas aulas); no terceiro ano, gravação áudio/exame, gravação áudio/conversação/laboratório, gravação áudio/aula (duas aulas), gravação áudio comentário e gravação áudio/exame conversação; e no quarto ano, gravação áudio/aula, gravação áudio/seminário (duas aulas), gravação áudio/ narrativa de história, gravação áudio/aula e gravação áudio/entrevista.

Os resultados do estudo de Cruz (2001) revelaram que a principal preocupação dos alunos se dá em relação ao uso de verbos. Muitos transferem o uso da LM para a LE, o que também ocorre no estudo aqui relatado quanto ao uso de cuando.

É possível pensarmos, nesse caso, que os alunos brasileiros, aprendendo espanhol, possam estar acionando procedimentos similares de processamento de ambos os códigos linguísticos, o que, segundo Koda (1997), remete a um princípio de semelhança que poderia facilitar a aquisição da língua-alvo, mas que sabemos que, nesse caso específico do uso do presente do subjuntivo, não facilitaria a aquisição para os aprendizes.

\section{O estudo realizado}

O estudo sobre transferência e a aprendizagem do presente do subjuntivo em espanhol foi realizado tendo como base a conjunção cuando, pois como já referido na introdução deste artigo, alunos brasileiros apresentam dificuldade ao conjugar verbos, no referido tempo verbal, com a conjunção adverbial temporal. Os alunos realizaram algumas atividades orais e escritas que exigiam o uso do presente do subjuntivo em espanhol. As atividades pensadas eram de preenchimento de lacunas, múltipla escolha, descrição de imagem e criação de 
história. Após a aplicação das atividades e a verificação da dificuldade encontrada, a pesquisadora e a professora titular planejaram duas aulas específicas sobre o uso do presente do subjuntivo com a conjunção cuando.

E, para fins de análise deste estudo, após intervenção linguística em oito horas aula, foi realizada a entrevista narrativa com os participantes. Tínhamos como objetivo, ao realizar a entrevista, compreender como os alunos entendiam o processo de aprendizagem de LE e verificar se os participantes realmente acreditavam na possibilidade da transferência linguística, ou seja, se a LM interferia na hora de aprender uma língua nova.

A pesquisa foi realizada em uma universidade privada do interior do estado do Rio Grande do Sul. Participaram da pesquisa doze alunos, estudantes de Letras espanhol. Todos os participantes estavam no sexto nível do curso de graduação e não eram nativos estrangeiros, nem haviam participado de intercâmbios acadêmicos ou de imersão linguística em espanhol.

Para a aplicação da entrevista narrativa, foi utilizado o programa Team $S p e a k^{5}$, que consiste em uma ferramenta de comunicação que possibilita conversas e gravação por voz com outros usuários utilizando a tecnologia Voz sobre IP (VOIP). É necessário um software para rodar o programa Team Speak e um servidor para os usuários se conectarem a canais para conversarem uns com os outros, ou seja, os alunos respondiam a questões específicas em um computador interligado a outro, e com a utilização de fones de ouvido e microfone, a investigadora pôde estabelecer uma conversa espontânea com todos os participantes.

Como este estudo apresenta um caráter de pesquisa qualitativa, acreditamos ser importante trazer a contribuição de Bogdan e Biklen (1994) sobre esse tipo de investigação. Para esses autores, a investigação qualitativa apresenta cinco características, a saber: a) a fonte direta de dados é o ambiente natural, constituindo o investigador como instrumento principal, isto é, os investigadores introduzem-se e permanecem grandes quantidades de tempo em escola, famílias, bairros e outros locais, tentando elucidar questões educativas; b) a investigação qualitativa é descritiva, ou seja, os dados recolhidos são em forma de palavras ou imagens e não de números; c) os resultados escritos da investigação contêm citações feitas com base nos dados para ilustrar e substanciar a apresentação; d) os investigadores qualitativos interessam-se mais pelo processo do que simplesmente pelos resultados ou produtos; e) os investigadores qualitativos tendem a analisar os seus dados de forma indutiva, ou seja, não recolhem dados ou provas com o objetivo de confirmar hipóteses construídas previamente; ao invés disso, as abstrações são construídas à medida que os dados particulares que foram recolhidos vão se agrupando; f) o significado é de importância vital na abordagem qualitativa; isto é, os investigadores preocupam-se com aquilo que se designa por perspectivas participantes. 
Em termos gerais, segundo os autores supracitados, os investigadores qualitativos estabelecem estratégias e procedimentos que lhes permitam levar em consideração as experiências do ponto de vista do informador. $\mathrm{O}$ processo de condução de investigação qualitativa reflete uma espécie de diálogo entre os investigadores e os respectivos sujeitos, o qual se dará com mais ênfase durante a entrevista narrativa.

\section{Principais resultados da entrevista narrativa}

Como descrito anteriormente, a entrevista narrativa foi realizada com os alunos a fim de verificar se os aprendizes de espanhol perceberam o papel da intervenção do professor titular e da pesquisadora para a aquisição do presente do subjuntivo e se perceberam a interferência ou não da transferência linguística do português ao espanhol no processo de aprendizagem.

A seguir, apresentamos as questões específicas realizadas durante a entrevista narrativa, bem como uma amostra da análise qualitativa realizada por uma das autoras deste artigo.

Para a pergunta 1, Como você se sentia ao utilizar o presente do subjuntivo em espanhol antes e como se sentiu depois das aulas da professora titular e da pesquisadora?, selecionamos as seguintes respostas:

Eu me sinto mais segura, pois agora eu sei a fala correta de como usar. (Maria ${ }^{6}$ )
Me senti muito mais segura em relação ao conteúdo, e acredito que adquiri muito mais conhecimento e tirei dúvidas. (Clara) Antes das aulas eu não sabia como usar bem o presente do subjuntivo, já tinha aprendido na aula, mas não conseguia passar para a fala. E agora me sinto mais segura quando uso. (Priscila)

Eu me sinto ..............mais segura pra poder falar espanhol. Acredito que as aulas ficaram mais que a gente vivência isso na prática falando em...me sinto melhor. (Carla)

Bom. Antes eu tinha algumas dúvidas, depois eu consegui saná-las, aprendi algumas coisas bastante importantes....assim frente a estrutura do verbo...exemplo não se utiliza infinitivo com o "cuando", como acontece em português. Isso é bastante importante. (Joana)

Me sinto muito mais seguro na utilização do presente do subjuntivo. Não sabia como caracterizar nem como conjugar, principalmente os verbos irregulares. (João)

Depois da aula a gente percebeu que nós aprendemos pouco antes, que não tínhamos conhecimento tanto, agora a gente aprendeu, temos mais conhecimento....deu uma clare$z a$. (Evelin)

Olha, eu me sinto um pouco mais segura agora. Ahaha antes eu não tinha ideia do que era o presente do subjuntivo. A gente passou muito rápido....agora eu tenho ideia de como funciona e como usá-lo em espanhol. Antes eu usava como em português. (Pâmela)

Podemos perceber a insegurança que os informantes tinham antes da intervenção em utilizar o presente do subjuntivo em espanhol. Muitos relataram não ter nem sequer ideia do que era o presente do subjuntivo e como acontecia a conjugação verbal ou que utilizavam como falavam em português. Pensamos que isso possa ter acontecido em razão de que as aulas da universidade prezam por um ensino mais comunicativo, voltado 
para a situação em uso, o que resulta em pouca atenção à gramática.

Assim, notamos a necessidade de um estudo mais focado, com atividades e exercícios mais específicos na estrutura gramatical alvo. Muitos participantes relataram o quanto foi benéfico o foco na estrutura, neste caso, no presente do subjuntivo em espanhol, quando trouxemos atividades específicas sobre isso, pois passaram a ter ideia de como funciona, como deve ser utilizado e em quais situações.

Nesse sentido, concordamos com as ideias de Gass e Selinker (2008), uma vez que os autores acreditam que a gramática deve ser ensinada por meio de atividades que permitam ao estudante ter consciência dos conteúdos, estimulando a aprendizagem das diferenças entre as línguas, como podemos perceber na fala dos seguintes informantes:

Não sabia como caracterizar nem como conjugar, principalmente os verbos irregulares; aprendi algumas coisas bastante importantes....assim frente a estrutura do verbo...exemplo não se utiliza infinitivo com o "cuando", como acontece em português. Isso é bastante importante. (Joana)

Observamos que os aprendizes não nativos de espanhol têm que ativar, de forma consciente, uma série de conhecimentos léxicos e sintáticos, como podemos demonstrar na seguinte fala:

...antes eu não tinha ideia do que era o presente do subjuntivo. (Carla)

$\mathrm{E}$, sabemos que muitas vezes esse acionar consciente somente acontece com o ensino explícito de gramática.
Para a questão 2, O que você achou das aulas específicas sobre o presente do subjuntivo em espanhol?, temos os seguintes relatos:

Eu achei muito boas, pois foram usados diferentes métodos. (Maria)

Esclarecedoras e me ajudaram a entender melhor como funciona o espanhol e o português. (Ana)

Achei muito, muito produtivas. Deu para memorizar bem e já deu pra começar falar naturalmente. (Priscila)

Eu achei no começo meio difícil da gente assimilar...porque a gente já tava acostumado a falar como no português né, mas foi uma evolução no falar e escrever corretamente. (Carla)

Bom, pra mim como acadêmica e futura professora bastante importante porque agora no processo principalmente quando vamos para sala de aula terei de abordar uma temática né, então esclareceu as minhas dúvidas e reforçou o que eu já sabia...também além disso aprendi o que eu não sabia. (Joana)

Achei interessante e o modo como foi dado também me agradou, foi um modo diferente e conseguiu que a gente se interessasse pela disciplina. (João)

Achei bem válidas....tinha de ter sido assim desde sempre. (Evelin)

Quanto às respostas para a questão 2 , podemos perceber o desejo de ter aulas mais voltadas para a gramática $\mathrm{e}$ a questão da transferência em si, o que vai ao encontro das ideias de Villalba (2002), fundamentais para este estudo, que sugere que o ensino da gramática especificamente pode se dar por intermédio do ensino direto da língua, como no ensino de regras gramaticais, e que a transferência não é apenas um fenômeno 
linguístico, mas também é uma estratégia de aprendizagem. Notamos que os informantes se sentiram mais confiantes a partir da intervenção da professora titular e da pesquisadora. Muitos, inclusive, afirmam que, como serão professores de espanhol, precisam dominar o que irão ensinar e saber explicitamente aquilo que estão ensinando ou usando na LE.

Outros informantes relataram seu ponto de vista quanto à abordagem empregada, que deu ênfase ao ensino explícito. Acreditamos que o fato de termos utilizado o programa de voz Team Speak tenha incentivado a aprendizagem, pois oportunizamos aulas diferentes, em contextos diferentes, saindo da rotina à qual os alunos estavam acostumados em sala de aula. As mudanças de atividades e de contexto motivaram os alunos, contribuindo para uma aprendizagem mais proveitosa, mesmo que os exercícios tenham sido voltados para a estrutura gramatical.

Quanto à pergunta 3, Em relação às tarefas, quais você gostou mais ou menos? Por quê?, selecionamos os seguintes comentários:

As que eu mais gostei foram as tarefas da plataforma, pois ahaha foi usada uma ferramenta diferente das usuais. (Maria)

Foram as gravadas e as de assinalar, porque ahaha gostei ahaha das gravações. Foram bem interessantes. (Clara)

Gostei mais de fazer as gravações, pois foi uma nova experiência. (Ana)

Gostei mais das orais e escrever e gostei menos das de completar porque confunde as opções. (Priscila)
Bom. As que eu achei mais desafiadoras foram as orais e as que eu menos gostei foi as de completar o verbo. (Joana)

Gostei mais das tarefas de formular frases e das tarefas com textos escritos e orais. Pela dificuldade, faz com que o aluno pense mais, tenha uma iniciativa maior. (Luísa)

Todas as tarefas foram boas. As que mais me agradaram foram as de produção textual, pelo desafio de criar uma história. (João)

As tarefas orais eu gostei mais, pois faz com que a gente pratique o espanhol. (Pâmela)

Percebemos que os comentários em relação à questão 3 vão ao encontro das respostas da pergunta 2 , pois muitos voltam a reforçar o quanto a mudança de metodologia e de atividades foi favorável para a aprendizagem. Muitos relatam 0 quanto as atividades do programa Team Speak foram interessantes e, principalmente, o quanto as atividades orais foram bem aceitas, pois fez com que, de alguma maneira, eles utilizassem o espanhol.

Identificamos o quanto gostam de atividades que desafiam e que desenvolvem a autonomia em língua estrangeira, neste caso, em espanhol, pois repetidamente comentam que gostam das atividades orais e de produção, pois são tarefas que fazem com que eles realmente utilizem o que sabem e como sabem fazê-lo na língua-alvo. Nesse sentido, percebemos a importância da utilização do programa Team Speak, uma vez que houve oportunidades para a comunicação utilizando um aspecto específico da língua, o presente do subjuntivo, com um recurso de comunicação diferente, a gravação de voz, o que muitas vezes possibilitou a 
descontração e espontaneidade do aluno na hora de interagir.

Para a pergunta 4, Como você acredita que deva ser a aprendizagem de gramática em espanhol?, selecionamos as seguintes respostas:

Eu acho que deveriam ser como estas, usando diferentes métodos para fixar melhor o conteúdo. (Maria)

Acredito que deva ser explicado o seu uso e sua forma. (Clara)

Focada na forma e no uso. (Ana)

Eu acho que tem de ser ahha ...não tem que ter essa nomenclatura de...porque assusta né, mas e tem que trazer temas atuais do dia a dia da vivência do aluno que, as vezes, ele tá usando a gramática e nem se dá conta, a maioria das vezes. (Carla)

Acredito que o ensino da gramática, a aprendizagem da gramática, ela deve ser..... ela deve ser dinâmica e que proporcione nós aprendermos não só as terminações dos verbos, mas como se utiliza em português e espanhol e por que, qual o conceito.. e se possivel sempre ligada ao texto. (Joana)

Eu acredito que a aprendizagem deva ser uma coisa que aconteça naturalmente nas aulas, através dos contextos e que deve ser uma coisa natural e que a gente consiga internalizar isso, que não seja uma coisa que passe...e que a gente não saiba depois, mas que a gente consiga internalizar isso no dia a dia. (Jussara)

Acredito que deva ser dado de forma.....menos taxativa, deva ser mais.. deva ser dado de um modo mais prático, como foi e um modo que as pessoas consigam entender e não se assustem por ser gramática. (João)

Eu acho que ela tem de ser de princípio ahaha como se a gente fosse ahaha porque a gente tem essa dificuldade porque a gente não aprendeu essa língua, então eu acho que a gente deva aprender passo por passo como ela funciona. (Evelin)
Eu acredito que deva ser mais aprofundada, porque nós passamos muito rápido e a gente acaba não aprendendo o que realmente é importante, o que é interessante para futuros professores. (Pâmela)

Percebemos que a maioria dos futuros professores relata o quanto é importante explicar a forma e o uso do aspecto gramatical em estudo. Uma explicação para essa crença pode ser o fato de que nem sempre o aluno tem a capacidade de identificar a estrutura gramatical da LE que está sendo estudada, ou seja, se for levado em consideração somente o aspecto comunicativo, é possível que a aprendizagem não ocorra, como relatado pelos informantes Jussara, Pâmela e Clara, o que é exemplificado a seguir:

...que a aprendizagem deva ser uma coisa que aconteça naturalmente nas aulas, através dos contextos e que deve ser uma coisa natural e que a gente consiga internalizar isso, que não seja uma coisa que passe...e que a gente não saiba depois. (Jussara)

que deva ser mais aprofundada, porque nós passamos muito rápido e a gente acaba não aprendendo o que realmente é importante, o que é interessante para futuros professores. (Pâmela)

acredito que deva ser explicado o seu uso e sua forma. (Clara)

Ao nos depararmos com percepções como essas, evidenciamos que a aprendizagem da gramática também pode interagir com a experiência de vida, ou seja, aprendizes mais velhos podem ser mais afetados pela saliência da forma morfológica do que aprendizes mais jovens, ou seja, os mais velhos dependem mais da aptidão verbal e da aprendizagem espe- 
cífica de gramática da LE. Isso deve ter suas origens em métodos ou abordagens de ensino que conheceram no passado.

Embora os participantes relatem que a gramática deve ser internalizada, notamos uma contradição, uma indecisão em suas falas, pois também dizem que a aprendizagem deve ser natural e em contextos relacionados a textos, como no relato a seguir da Joana:

Acredito que o ensino da gramática a aprendizagem da gramática ela deve ser.....ela deve ser dinâmica e que proporcione nós aprendermos não só as terminações dos verbos, mas como se utiliza em português e espanhol e por que, qual o conceito...e se possivel sempre ligada ao texto. (Joana)

Podemos dizer que notamos, nesta fala, certa insegurança e acreditamos que o ensino de gramática e o insumo às estruturas subordinadas não deva ser adiado, colocando assim o aluno em situações de uso reais.

E, para finalizar, selecionamos algumas respostas quanto à questão 5: Por serem o português e o espanhol línguas próximas, você acredita que quem fala português aprende espanhol mais facilmente?

Eu acredito que sim, porque os sons são parecidos e eu acho que facilita mais ahaha a pronúncia, às vezes de algumas letras, palavras às vezes também tem o mesmo significado. Eu acredito que sim. (Maria)

Acho que compreende o espanhol mais facilmente, mas na parte da gramática acaba confundindo bastante porque acha que é parecido, mas muita coisa é diferente. (Priscila)

Eu acredito que tem uma proximidade, principalmente na gramática, mas não necessariamente seja mais fácil de aprender. Por essa proximidade talvez as regras gra- maticais, às vezes confundem, mas não torna mais fácil não. (Carla)

Acredito que possa sim aprender mais facilmente a língua espanhola, porém como aprendemos facilmente confundimos facilmente, porque nós temos essa percepção...já está formada...por exemplo a gramática na nossa cabeça aí na língua espanhola... a gente vai meio por assimilação e às vezes acabamos nos equivocando assim né, como o uso do subjuntivo né, que em língua portuguesa é de uma maneira e em língua espanhola é diferente. (Joana)

Eu acho que.....depende de cada um, de cada aluno, do esforço de cada um. Independente de ser nativo da língua portuguesa ou não. Acho que sim, pois algumas poucas palavras se parecem, o que torna mais fácil a aprendizagem. (Luísa)

Eu acredito que há uma facilidade, mas que os alunos....as pessoas que estão aprendendo não podem se basear nisso dispensando, pensando que não é necessário estudar...porque têm muitas diferenças e muitas coisas que não são tão semelhantes e que o aprendizado da língua ele é mais do que só essas semelhanças, então, facilita, facilita, sim, mas tem que estudar. (Jussara)

Acredito que não, porque elas são muito próximas, então acaba virando bastante um portunhol, não é ....tu tem que estudar bastante pra não confundir as duas línguas. Diferente do inglês que é totalmente diferente e tu vai conseguir falar. $O$ espanhol por essa proximidade acaba sendo mais difícil. (Evelin)

Eu acho que não, porque eu tenho a minha experiência, que eu achei muito difícil aprender...acho que qualquer língua diferente da nossa é difícil de aprender. (Fabiane)

Ahaha não acredito que seja, pois apesar delas serem parecidas têm muitas palavras que enganam. Têm outras línguas também que são parecidas, mesmo assim creio que não seja por isso mais fácil. (Pâmela)

Ficou evidenciado, então, que alguns informantes acreditam que haja uma 
similaridade entre o português e o espanhol, o que respalda as observações de Koda (1997), que assevera que algumas línguas podem ser consideradas mais similares entre si do que outras, como no caso do português e espanhol. Segundo a autora, essa similaridade pode estar relacionada com o uso de determinados mecanismos de processamento da língua na aprendizagem. Essa proximidade linguística acionaria procedimentos similares de processamento de ambos códigos linguísticos, o que, para Koda, seria uma princípio de semelhança facilitador de aquisição e ocasionaria uma melhor competência do aprendiz.

Mas, percebemos que os alunos ainda estão confusos quanto à facilidade ou não em aprender o espanhol. No entanto, evidencia-se que a grande maioria acredita que, para aprender uma língua estrangeira, é necessário muito estudo, principalmente em se tratando de uma língua próxima ao português, o que pode ser um fator causador de confusão linguística e da possibilidade de que aconteça a transferência para a LE.

\section{Considerações finais}

A questão da transferência esteve presente, como base para este estudo, pois uma das primeiras hipóteses levantadas era a de que os alunos se utilizavam da LM para realizar a atividade proposta (KODA, 1997) em LE, pelo fato de ambas as línguas, português e espanhol, apresentarem uma similaridade. Hipó- tese que se confirmou na realização da entrevista narrativa, pois os alunos não tinham segurança, muitas vezes, no uso do presente do subjuntivo em espanhol, como podemos verificar nas respostas selecionadas e, praticamente, responde à pergunta central deste estudo: a língua materna (português do Brasil) é fator de interferência na produção oral e escrita do presente do subjuntivo em espanhol por alunos brasileiros?

Pudemos observar, também, ao longo do artigo, que a utilização do programa Team Speak para a realização da entrevista narrativa levou a uma reflexão dos participantes quanto à forma e aos recursos utilizados por professores ao ensinar uma LE. O fato de utilizar recursos e métodos diferentes do quadro e giz motivou os alunos e despertou interesse e vontade de planejar atividades diferenciadas para a aprendizagem de espanhol.

Somado a isso, percebemos nos relatos dos participantes, durante a entrevista narrativa, o quanto a atividade de gravação de voz foi benéfica, pois os participantes expuseram opiniões e intensificaram o pensamento de que somente uma metodologia de ensino não dá conta com eficiência da aprendizagem de espanhol. Para os participantes, futuros professores de espanhol, faz-se necessário, em algum momento da aula, o ensino mais específico e intensivo da gramática da língua-alvo, especialmente com a utilização de recursos diferenciados, o que atenderia a diferentes estilos de aprendizagem. 
Nesse sentido, este estudo tem a intenção de esboçar uma análise para o fenômeno da transferência, que concilia a definição com a ideia apresentada por Selinker (1972) e, contribui ainda, para a investigação na área de ensino e aprendizagem de LE por meio de discussões sobre transferência e o ensino de gramática de LE, uma questão pertinente à prática docente dos estudantes de espanhol, futuros professores.

\section{A qualitative investigation about transfer in the learning of Spanish by Brazilian students}

\begin{abstract}
The present study focuses on language transfer from Brazilian Portuguese to Spanish, taking into account the present of the subjunctive with conjunction cuando. The data were collected in a university language course in a private institution in the south of Brazil. Oral and written activities were applied during the process. The Team Speak Program was employed as a pedagogical tool to conduct narrative interviews with the students involved. Learner perceptions bring evidence to the relevance of the selected linguistic items and the benefit of using Team Speak Program as a helping tool in the learning of the target language.
\end{abstract}

Keywords: Transfer. Present of subjunctive. Team Speak. Narrative interview. Spanish.

\section{Notas}

1 Nesta investigação, os termos "aprendizagem" e "aquisição" são usados indistintamente.

2 Neste estudo, as expressões língua estrangeira (LE) e segunda língua são usadas indistintamente no que se refere ao processo de aquisição da língua alvo.

3 Entende-se erro como hipótese, ou seja, como língua em desenvolvimento, em processo de aquisição.

4 Consiste em quinze conjuntos de seis palavras cada, listadas na coluna da esquerda que devem ser reconhecidas e combinadas com as explicações (sinônimos, paráfrases) dadas na coluna da direita.

5 As epecificações técnicas do programa Team Speak estão disponíveis em: <http://www.teamspeak.com/?page=teamspeak3>.

6 Todos os nomes são fictícios para preservar as identidades dos alunos.

\section{Referências}

BOÉSSIO, C. P. D. A transferência indevida do infinitivo flexionado no ensino do espanhol para brasileiros. 2003. 96 f. Dissertação (Mestrado em Letras) - Universidade Católica de Pelotas, Pelotas, 2003.

BOGDAN, R. C.; BIKLEN, S. K. A investigação qualitativa em educação: uma introdução à teoria e aos métodos. Porto, PT: Porto Editora, 1994.

CORDER, S. P. The significance of learner's errors. International Review of Applied Linguistics, Heidelberg/Germany, n. 4, p. 161-170, 1967.

COSTA. G. V. M. O uso do presente do modo subjuntivo em língua espanhola: contribuição para aprendizes brasileiros. 2004. $122 \mathrm{f}$. Dissertação (Mestrado em Letras) - Universidade Católica de Pelotas, Pelotas, 2004.

CRUZ, M. L. O. B. Estágios de interlíngua: estudo longitudinal centrado na oralidade de sujeitos aprendizes de espanhol. 2001. $326 \mathrm{f}$. Tese (Doutorado em Linguística Aplicada) 
- Universidade Estadual de Campinas, Campinas, 2001.

ELLIS, R. Uptake as language awareness. Language Awareness, Amsterdam, n. 4, p. 174-159, 1995.

GASS, S.; SELINKER, L. The role of the native language: an historical overview. In: GASS, S.; SELINKER, L. (Org.). Second language acquisition: an introductory course. New York: Tayler \& Francis, 2008. p. 89-120.

JARVIS, S. Methodological rigor in the study of transfer: identifying L1 influence in the IL lexicon. Language Learning, v. 58, n. 2, p. 245-309, 2000.

KODA, K. Orthographic knowledge in L2 lexical processing: a cross-linguistic perspective. In: COADY, J.; HUCKIN, T. Second language vocabulary acquisition. Cambridge: Cambridge University, 1997. p. 117-134.

LAUFER, B. The development of passive and active vocabulary in a second language: same or different? Applied Linguistics, Heidelberg/ Germany, v. 19, n. 2, p. 255-271, 1998.

LONG, M. Focus on form: a design feature in language teaching methodology. In: DE BOT, K. et al. (Ed.). Foreign - language research in cross-cultural perspective. Amsterdam: Benjamins, 1991. p. 39-52.

MITCHELL, R.; MYLES, F.; MARSDEN, E. Second language learning theories. $3^{\text {th }}$ ed. London: Routledge, 2013.

ODLIN, T. Language transfer: cross-linguistic influence in language learning. Cambridge: Cambridge University, 1989. p. 1-18.

SCHACHTER, J. Classroom interaction, comprehension and the acquisition of $\mathrm{L} 2$ word meanings. In: HARLEY, B. (Ed.). Lexical issues in language learning. Michigan: Ann Arbor, 1995. p. 202-232.

SELINKER, L. Rediscovering interlanguage. London: Longman, 1992.
TEAM SPEAK. Disponível em: <http://www. teamspeak.com/?page=teamspeak $3>$. Acesso em: 30 mar. 2013.

VILLALBA, T. K. B. Pepe vio que no tiene jeito, su mujer es asímismo: as delicadas relações lexicais entre a L1 e a L2 na aquisição de español por universitários brasileiros. 2002. 224 f. Tese (Doutorado em Linguística Aplicada) - Universidade Federal do Rio Grande do Sul, Porto Alegre, 2002. 